Vol tammet ri c det er mi nat i on of concent $r$ at $i$ ons of fer rocene-i ncl uded ni trobenzene dropl et s i $n$ wat er

\begin{tabular}{|l|l|}
\hline 著者 & $\begin{array}{l}\text { LI Nengj uan, AOK Koi chi , CHEN Ji ngyuan, } \\
\text { N SH UM Toy ohi ko }\end{array}$ \\
\hline $\begin{array}{l}\text { j our nal or } \\
\text { publ i cat i on ti tl e }\end{array}$ & Journal of el ect r oanal yt i cal chemi st ry \\
\hline year & $2011-04$ \\
\hline URL & ht t p: //hdl . handl e. net /10098/3208 \\
\hline
\end{tabular}




\title{
Voltammetric determination of concentrations of ferrocene-included nitrobenzene droplets in water
}

\author{
Mengjuan Li, Koichi Aoki ${ }^{*}$, Jingyuan Chen, Toyohiko Nishiumi \\ Department of Applied Physics, University of Fukui, 3-9-1 Bunkyo, Fukui-shi, 910-8507
}

Japan

\begin{abstract}
When a nitrobenzene (NB) phase came in quiescent contact with a water phase, water-droplets were formed spontaneously near the oil|water interfaces (Electrochem. Commn. 11 (2009) 239). We reported here quantitative data of the NB-droplets by use of UV-absorbance, dynamic light scattering (DLS) and voltammetry with a help of ferrocene. The supernatant separated spontaneously from the oil-water mixture

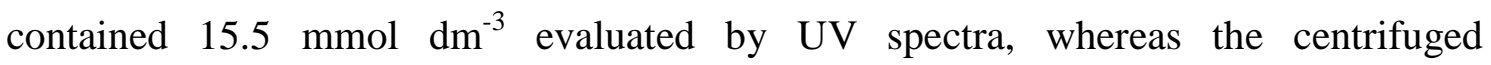
supernatant did $9.3 \mathrm{mM}$. The difference suggested the presence of NB-droplets, the diameter of which ranged $0.15-0.5 \mu \mathrm{m}$ obtained by DLS. Ferrocene was dissolved deliberately in the aqueous solution and the NB solution up to saturation. The voltammograms in the ultrasonicated supernatant exhibited diffusion-controlled redox peaks of ferrocene, which should be supplied from both dissolved ferrocene and ferrocene-dissolved NB droplets. The former was 1/3.6 times of the latter by the comparison with the current of ferrocene-saturated aqueous solution. Applying the expression for the diffusion-controlled peak current of a big particle, we estimated the number concentration of NB droplet to be $1.1 \times 10^{14} \mathrm{dm}^{-3}$. This value is equivalent to the average distance, $L=2.1 \mu \mathrm{m}$, between neighboring two droplets, corresponding to the diffusional traveling time, $L^{2} / D=1.3 \mathrm{~s}$, which would be long enough for collision of droplets to stabilize the emulsions.
\end{abstract}

key words: spontaneous emulsification; oil|water interface; size of droplets; voltammetry of big particles

* Corresponding author, e-mail: kaoki@u-fukui.ac.jp 


\section{Introduction}

A mixture of water and hydrophobic oil takes either a phase-separated state or an emulsion [1]. The former is thermodynamically stable [2], whereas the latter is formed dynamically [3-5]. Emulsions are necessarily generated when phase-separated states are mixed vigorously. They sometimes are formed spontaneously even at quiescent contact, depending on conditions [6-9]. Emulsions have been found to coexist with phase-separated states for a long time [10] even without including surfactant at a quiescent contact [11]. This fact indicates that a stable mixture should take either a phase-separation or an emulsion, but does both of them. The coexistence has been theoretically supported by distributions of any size of droplets evaluated from statistical mechanics [12], as being in agreement with experimental results [10,11].

A model of ion transfer through oil|water interfaces is idealized to form a well-defined, flat, phase boundary [13-15]. Real voltammograms deviate from ideal ones [16] at the following points; reactions of adsorbed species at the interface [17-19], electron transfer reactions at the interface [20-22], ion transfer in micro-volumes like droplets [23], and mixed potentials due to simultaneous transfer of cations and anions [24]. If droplets are involved in the other phase, they may alter properties of the bulk or the interface, exemplified by induction of convection [25] or fluctuations of currents $[26,27]$ due to local difference in surface tension of adsorbed droplets, and by variations of drop size [3,4] due to compensation of the difference in pressure through Young-Laplace equation [28]. Revisit of the model of oil|water interfaces may be required not only for microscopically flatness of the interface of the molecular dynamics $[29,30]$ but also for ion-penetration [31- 37].

Before investigating effects of droplets formation on ion transfer voltammograms, we should know size distribution of droplets and their number concentrations, which may depend on solution conditions. Qualitative detection of droplets has been 
challenged by voltammetry when redox species was added to emulsions [38-42]. In order to determine concentrations of droplets, voltammetric currents should be related quantitatively with concentrations of droplets, droplet size and redox concentrations. From the electrochemical viewpoint, oil droplets containing redox species resemble suspended redox latex particles such as hydrogen ion in polystyrene latex [43], polyaniline-coated polystyrene [44-46], ferrocenyl derivatives on polystyrene $[47,48]$, and polyacrylic acid-polystyrene latex [49]. Redox latex particles react at electrodes by releasing redox moieties [43,47], propagating redox reactions in the latex particles [44-46], letting redox moieties diffuse in the latex particles [48] or contacting the spherical surface with electrodes $[49,50]$. In contrast, droplets including redox species cannot react at an electrode until they are adsorbed. They often change their geometry and sometimes coalesce [40]. A common feature is diffusion of latex particles and droplets caused by electrode reactions. This report is devoted to measurements of size distribution and the amount of nitrobenzene droplets in aqueous solution by use of DLS and UV-spectroscopy. Voltammetry is made in droplet-dispersed aqueous solutions including ferrocene as a redox marker. Combination of the DLS data with the voltammetric data evaluates the number concentration of the droplets.

\section{Experimental}

Nitrobenzene (Wako) was refined by adsorbing impurities with active alumina of 300 mesh, and filtering them. Ferrocene (Wako) was used after sublimation. Sodium

perchlorate and tetrabutylammonium perchlorate (TBAP) (Nakalai Tesque. Inc) were used as received for supporting electrolyte in water and NB solution, respectively,

A potentiostat, HECS-1112 (Fuso, Kawasaki) was used for cyclic voltammetry. Glassy carbon electrode $3 \mathrm{~mm}$ in diameter was purchased (BAS, Tokyo). The reference 
and the counter electrodes were $\mathrm{Ag} / \mathrm{AgCl}\left(3 \mathrm{M} \mathrm{KCl}, \mathrm{M}=\mathrm{mol} \mathrm{dm}{ }^{-3}\right)$ and platinum wire, respectively.

The size distribution was determined by a dynamic light scattering (DLS) instrument (Malvern Zetasizer Nano-ZS, UK). The UV-spectrometer was V-570 (JASCO, Tokyo). A centrifuge was SRX-201 (Tomy, Tokyo), which kept temperature of samples at $4{ }^{\circ} \mathrm{C}$.

\section{Results and Discussion}

\section{1. Spontaneously formed nitrobenzene-in-water emulsions}

It is not clear whether aliquots by addition of NB to the aqueous solution at concentrations less than the saturated concentration (14-17 mM [51]) might include NB droplets or not. A visual evidence of inclusion of droplets is generally turbidity of a solution, which is ascribed to light scattering by large droplets. The upper aqueous phase of the NB-water mixture was transparent by our eyes after vigorous mixing. A simple, quantitative measure of turbidity is a loss of transmittance of light by use of the UV-absorbance of NB. The absorbance may be expressed by $A=\varepsilon_{\mathrm{s}} c_{\mathrm{s}}+\varepsilon_{\mathrm{d}} c_{\mathrm{d}}$, where $c_{\mathrm{s}}, c_{\mathrm{d}}$ and $c$ are, respectively, number concentration of dissolved NB, that of droplets, and that of the added NB ( $c=c_{\mathrm{s}}+c_{\mathrm{d}}$ ). Here, $\varepsilon$ is the absorption coefficient of the added NB, $\varepsilon_{\mathrm{S}}$ is that of dissolved NB, and $\varepsilon_{\mathrm{d}}$ is that of NB droplets depending on the turbidity. If $c_{\mathrm{d}}$ and $c_{\mathrm{s}}$ were to be proportional to $c$, the absorbance should be also proportional to $c$. The ratio $c_{\mathrm{d}} / c$ is much smaller than $c_{\mathrm{s}} / c$ for low concentrations because of few possibilities of coalescence. Then we predict that $A=\varepsilon_{\mathrm{s}} C_{\mathrm{s}}+\varepsilon_{\mathrm{d}} C_{\mathrm{d}} \approx \varepsilon_{\mathrm{s}} C_{\mathrm{s}} \rightarrow \varepsilon_{\mathrm{s}} C$ for $c \rightarrow 0$. The relation of the absorbance with $c$ varies from non-proportionality to proportionality as $c$ tends to zero. In this prediction, we obtained the absorbance at $268 \mathrm{~nm}$ at various concentrations of NB-included water, and plotted it in Fig. 1. The concentration domain at which the 
absorbance was less than 2 was $c<0.3 \mathrm{mM}$, which is much lower than the saturated concentration. Proportionality was found for $c<0.06 \mathrm{mM}$, the slope of which gave the molar absorption coefficient, $1.0 \times 10^{4} \mathrm{M}^{-1}$. Deviation from the proportionality for $c>$ $0.08 \mathrm{mM}$ may be ascribed to light scattering by NB droplets. Since the errors of the absorbance for $0.7<A<2$ were less than 0.02 , the deviation was obvious. Consequently, $0.08 \mathrm{mM}$ is a threshold concentration of formation of droplets from the optical viewpoint.

The presence of NB droplets was examined with size distributions of droplets by DLS. The scattering light relative intensity vs. the diameter, $2 r$, showed a peak, like in Fig. 2. The appearance of one peak suggests narrow size distribution of droplets. The diameters of the droplets were plotted on the right axis against NB concentrations in Fig. 1. The diameter ranged from 0.2 to $0.6 \mu \mathrm{m}$, regardless of the concentrations, implying that droplets are formed under quasi-equilibrium conditions. The formation of the droplets is supported by the theory of the size distribution of droplets in emulsions by use of statistical mechanics [12]. The presence of droplets at concentrations less than $0.08 \mathrm{mM}$ seems inconsistent with the result of UV absorbance. However, the DLS result demonstrates only the presence of the droplets but does not provide any information on amounts of droplets. The concentration of droplets may be much smaller than $c_{\mathrm{s}}$ for $c<$ $0.08 \mathrm{mM}$.

Nitrobenzene was mixed with water at the volume ratio of 1:1 in an ultrasonicated bath. The mixture, which was retained quiescent for a few hours, showed clear two-phase separation. The upper aqueous phase was sampled for determining concentration of NB by UV. Since the absorbance was over 3, the supernatant was dissolved by 200 times with water. The concentration of NB was $15.5 \mathrm{mM}$ by use of the absorption coefficient obtained in Fig. 1, independent of the mixing procedures or volume ratios of water and NB. When the supernatant was centrifuged at $4.7 \times 10^{4} \mathrm{~g}$ in 5 minutes, the concentration of NB was decreased to $9.3 \mathrm{mM}$, which did not decrease 
with further centrifugation periods. Since centrifugation generally removes dispersed particles or droplets, the difference in the concentrations, $6.2 \mathrm{mM}$, should correspond to the NB droplets. Both the quiescently formed supernatant and the centrifuged supernatant exhibited size distributions of droplets in Fig. 2a and 2b, respectively, the diameters of which were ca. $0.5 \mu \mathrm{m}$ and $0.15 \mu \mathrm{m}$. The centrifugation spun down large droplets. The centrifugal force at the acceleration, $a$, acting on an oil droplet with radius, $r$, in water is given by $(4 \pi / 3) r^{3}\left(d_{0}-d_{\mathrm{w}}\right) a$, where $d_{\mathrm{o}}$ and $d_{\mathrm{w}}$ are densities of NB and water, respectively. When the droplet moves at a constant velocity, $u$, by the centrifugal force, the frictional force, $6 \pi \eta r u$, acts on the droplet. Balance of both the forces yields $u=$ $2 r^{2}\left(d_{\mathrm{o}}-d_{\mathrm{w}}\right) a / 9 \eta$. Values of $u$ at $2 r=0.5$ and $0.15 \mu \mathrm{m}$ are 0.14 and $0.013 \mathrm{~cm} \mathrm{~s}^{-1}$ for $a=$ $4.7 \times 10^{4} \mathrm{~g}$, respectively. The 5 min's centrifugation should move droplets by 42 and 3.8 $\mathrm{cm}$, respectively. The latter value is large enough for separating oil droplets in $10 \mathrm{~cm}$ cell height. The inseparability of $0.15 \mu \mathrm{m}$ droplets may be ascribed to the Brownian dispersion.

In contrast to the NB droplets, the oil phase in contact with water contained visible water droplets. The diameters ranged from 1 to $5 \mu \mathrm{m}$, as were consistent with values in the previous report [11]. The DLS data (Fig. 2c) showed diameters close to those by the optical microscope. The diameter of water droplets larger than that of NB droplets may be related with much larger solubility of water in NB (3 M [52]) than the solubility of NB in water (0.015 M).

\section{2. Voltammograms of emulsions}

Ferrocene was dissolved deliberately into $0.4 \mathrm{M} \mathrm{NaClO}_{4}$ aqueous solution and 0.4 M tetrabutylammonium perchlorate NB solution with ultrasonication until solid of ferrocene was left in each solution. Each solution was centrifuged at $4.7 \times 10^{4} \mathrm{~g}$ to remove the solid ferrocene. The NB solution of $5 \mathrm{~cm}^{3}$ was mixed with the $95 \mathrm{~cm}^{3}$ 
aqueous solution in the ultrasonic bath to form a turbid emulsion. Voltammograms of the emulsion were obtained at the glassy carbon electrode $3 \mathrm{~mm}$ in diameter (Fig. 3). Anodic and cathodic peaks were observed in the domains $0.45-0.50$ and $0.25-0.30 \mathrm{~V}$, respectively. The effect of scan rates on the peak potentials is ascribed to the addition of NB droplets. This may be caused by an increase in solution resistance of NB droplets or NB film on the electrode. Plot of the anodic and the cathodic peak currents against their peak potentials fell on each line, as shown in Fig. 3, according to the technique of evaluating accurately a peak potential without IR-drop [53]. The slopes were approximately common, indicating that the potential shift with the scan rates should be caused by solution resistance. The difference between the cathodic and the anodic peak potentials extrapolated to $I=0$ was $80 \mathrm{mV}$, close to the diffusion-controlled reversible reaction. The cathodic peak potential may depend on solubility of ferricenium salt and ferrocene, and thus detailed discussion is meaningless. The peak potentials $(0.42,0.34$ V) extrapolated to $I=0$ are closer to those of ferrocene in NB $(0.47,0.55 \mathrm{~V}$ [54]) than those in water $(0.15,0.23 \mathrm{~V})$.

The anodic peak current, $I_{\mathrm{p}}$, at the first scan was plotted against the square root of the potential sweep rate, $v$ in Fig. 4(a). The proportionality for $v<0.1 \mathrm{~V} \mathrm{~s}^{-1}$ suggests the diffusion controlled process of the peak current. In contrast, the plot deviated to low values from the proportionality for $v>0.3 \mathrm{~V} \mathrm{~s}^{-1}$. The diffusion-controlled current for $v>$ $0.3 \mathrm{~V} \mathrm{~s}^{-1}$ might be larger than $50 \mu \mathrm{A}$, according the proportional line in Fig. 4. Then the IR-drop would be over $0.2 \mathrm{~V}$ from the extrapolated line to $I_{\mathrm{p}}>50 \mu \mathrm{A}$ in Fig. 3. Such a large potential shift corresponds to net slower scan rate, and hence the peak currents for $v>0.3 \mathrm{~V} \mathrm{~s}^{-1}$ in Fig. 4 are deviated from the proportional line.

The centrifuged supernatant, being the transparent aqueous phase, showed the voltammogram in Fig. 5a, which was similar to the voltammograms in Fig. 3 except for the potential shift. The anodic peak current was proportional to $v^{1 / 2}$ (Fig. 4(b)), indicating the diffusion control. The oxidation current should be provided by both 
ferrocene dissolved in water and ferrocene dissolved in NB droplets. In order to estimate an amount ratio of the two components, we carried out voltammetry of ferrocene-saturated aqueous solution including $0.4 \mathrm{M} \mathrm{NaClO}_{4}$ (Fig. 5(b)). The peak potentials of ferrocene in the centrifuged supernatant of the emulsion were the same as those in ferrocene-saturated aqueous solution. The peak current was diffusion-controlled from the proportionality of $I_{\mathrm{p}}$ vs. $v^{1 / 2}$ (Fig. 4(c)). The value of the slope of the proportionality was by $1 / 3.6$ times of that for centrifuged supernatant. Therefore, the voltammetric current ratio of ferrocene dissolved in water to ferrocene in NB droplets is 1 : 2.6. This is not equivalent to the concentration ratio $\left(c_{\mathrm{s}}: c_{\mathrm{d}}\right)$ because voltammetric currents depend not only on the concentration but also on the diffusion coefficients of ferrocene and the droplets. The peak potentials of ferrocene in the centrifuged supernatant of the emulsion were the same as those in ferrocene-saturated aqueous solution. Thus the standard potential of the former, $F E^{0}$ (centrifuge) = $\mu^{\mathrm{O}}\left(\mathrm{Fc}^{+}(\right.$centrifuge $\left.)\right)-\mu^{\mathrm{O}}(\mathrm{Fc}($ centrifuge $))$, is close to that of the latter, $E^{\mathrm{O}}\left(\mathrm{H}_{2} \mathrm{O}\right)=$ $\mu^{\mathrm{o}}\left(\mathrm{FC}^{+}\left(\mathrm{H}_{2} \mathrm{O}\right)\right)-\mu^{\mathrm{o}}\left(\mathrm{Fc}\left(\mathrm{H}_{2} \mathrm{O}\right)\right)$, where $\mu^{\mathrm{o}}$ means the standard chemical potential in the state designated by the parentheses. The equality, $E^{\mathrm{o}}$ (centrifuge) $=E^{\mathrm{o}}\left(\mathrm{H}_{2} \mathrm{O}\right)$, does not mean $\mu^{\mathrm{o}}\left(\mathrm{Fc}^{+}(\right.$centrifuge $\left.)\right)=\mu^{0}\left(\mathrm{Fc}^{+}\left(\mathrm{H}_{2} \mathrm{O}\right)\right)$, but NB contributes equally to the chemical potentials of $\mathrm{Fc}^{+}$and $\mathrm{Fc}$. In contrast, the standard potential in NB is given by $F E^{0}(\mathrm{NB})=$ $\mu^{\mathrm{O}}\left(\mathrm{Fc}^{+}(\mathrm{NB})-\mu^{\mathrm{O}}(\mathrm{Fc}(\mathrm{NB}))\right.$. The experimental result was approximately $E^{\mathrm{o}}(\mathrm{NB})=$ $E^{0}\left(\mathrm{H}_{2} \mathrm{O}\right)+0.20 \mathrm{~V}$. Since $\mathrm{Fc}$ is hydrophobic, $\mu^{\mathrm{O}}\left(\mathrm{Fc}\left(\mathrm{H}_{2} \mathrm{O}\right)\right)$ may be higher than $\mu^{\mathrm{o}}\left(\mathrm{Fc}^{+}\left(\mathrm{H}_{2} \mathrm{O}\right)\right), \mu^{\mathrm{o}}\left(\mathrm{Fc}^{+}(\mathrm{NB})\right.$ and $\mu^{\mathrm{O}}(\mathrm{Fc}(\mathrm{NB}))$. This is an explanation of the potential shift of the midpeak value by $0.2 \mathrm{~V}$.

\subsection{Evaluation of number concentration of NB droplets}

Although the DLS measurement of the centrifuged supernatant showed uniform diameter $0.15 \mu \mathrm{m}$ of NB droplets (Fig, 2(b)), it did not provide the number 
concentration of droplets. We shall estimate the concentration by use of the voltammetric currents, combining them with the diameter of the droplets. When a particle contains $m$ molecules of a redox species with one-electron transfer, the expression for the diffusion-controlled peak current is given by [55]

$$
I_{\mathrm{p}}=0.446 F A m c_{\mathrm{d}} \sqrt{D v F / R T}
$$

where $c_{\mathrm{d}}$ is the bulk concentration of the particle (droplet) and $D$ is the diffusion coefficient of the particle. Variable $m$ corresponds to the number of ferrocene molecules per NB droplet.

The concentration of ferrocene in the droplet may be close to the saturated one, because the emulsion was generated under the ferrocene-saturated condition. From the UV-absorbance, the saturated concentration was $0.67 \mathrm{M}$. Consequently we estimate $m$ to be $0.67 \mathrm{M} \times(4 \pi / 3) r^{3} N_{\mathrm{A}}=7.1 \times 10^{5}$ for $2 r=0.15 \mu \mathrm{m}$, where $N_{\mathrm{A}}$ is the Avogadro constant. The diffusion coefficient of the droplet was estimated from the Stokes-Einstein equation $\left(D=k_{\mathrm{B}} T / 6 \pi \eta r\right)$ for the viscosity of water, $\eta=0.89 \mathrm{mPa}$ s. It was $3.3 \times 10^{-8} \mathrm{~cm}^{2} \mathrm{~s}^{-1}$. Since $I_{\mathrm{p}}$ in Eq.(1) is equal to 2.6 times the peak current in the supernatant, we evaluated the number concentration of the droplets $\left(c_{\mathrm{d}}\right)$ from Eq. (1) to be $1.1 \times 10^{14} \mathrm{dm}^{-3}$, which is equivalent to the average distance, $L=\left(c_{\mathrm{d}} N_{\mathrm{A}}\right)^{-1 / 3}=2.1 \mu \mathrm{m}$, between closest neighboring droplets. If a droplet moves in the distance by diffusion to coalesce, it takes $t_{1}=L^{2} / D=$ $1.3 \mathrm{~s}$ for the travelling. This period is too long for droplets to collide with each other, resulting in the stable emulsion. We estimate a time of coalescing droplets by one-dimensional motion in a macroscopic cell, as an example. As a result of the coalescence of two droplets, the distance between neighboring closest two-coalescing droplets is $4.2 \mu \mathrm{m}$. Then the droplet volume doubles or the radius increases $2^{1 / 3}$ times. The diffusion coefficient decreases $2^{1 / 3}$ times. It takes $t_{2}=(2 L)^{2} /\left(2^{-1 / 3} D\right)$ to make two duplicate droplets coalesce. In general, the coalescence at $n$-times requires the moving distance, $2^{n-1} L$ with the diffusion coefficient, $2^{-(n-1) / 3} D$. It takes $t_{n}=\left(2^{n-1} L\right)^{2} /\left(2^{-(n-1) / 3} D\right)$ for 
the $n$-multiplying droplet to diffuse. Coalescence periods at cells $1 \mathrm{~mm}$ and $1 \mathrm{~cm}$ long become 40 days and 14 years, respectively.

If ferrocene in the centrifuged supernatant were not to be localized to NB droplets but were to be distributed uniformly at a molecular level, the average concentration might be $m / N_{\mathrm{A}} L^{3}=0.13 \mathrm{mM}$. This value is by 40 times larger than the saturated concentration of ferrocene in water $(0.003 \mathrm{mM}$ evaluated from the slope of line (c) in Fig. 4).

\section{Conclusions}

Transparent, NB-mixed water contains dissolved NB and NB droplets 0.15-0.5 $\mu \mathrm{m}$ in diameter for any concentration, according to DLS. The UV-absorbance of NB-mixed water deviates lower from the proportionality to the concentration because of light scattering by formation of droplets. It shows proportionality for concentrations less than $0.08 \mathrm{mM}$. The concentration of the droplets is proportional to the concentration of added NB.

Voltammetric peak currents in the aliquots by addition of NB to the aqueous solution were controlled by diffusion of dissolved ferrocene molecules and ferrocene-included NB droplets. They depend on not only their concentrations but also their diffusion coefficients. Separation of the current into the two with the help of diameter of droplets allowed us to estimate the number concentration of droplets. The average distance between neighboring droplets was large enough for coalescence through diffusion of droplets.

\section{Acknowledgement}

This work was financially supported by Grants-in-Aid for Scientific Research (Grants 22550072) from the Ministry of Education in Japan. 


\section{Figure Captions}

Fig. 1 Concentration variation of UV-absorbance on the left axis and diameters of droplets of NB-included aqueous solutions on the right axis.

Fig. 2. Size distributions of NB droplets in the upper water phase of the emulsion (v/v of water to NB is 20/1) (a), centrifuged supernatant (b) and water droplets in NB phase (c), obtained by DLS.

Fig. 3. Voltammograms of the $\mathrm{O} / \mathrm{W}$ emulsion (volume fraction of the NB was 0.05) including saturated ferrocene and $0.4 \mathrm{M} \mathrm{NaClO}_{4}$ in both phases at the glassy carbon electrode $3 \mathrm{~mm}$ in diameter at scan rate $v=$ (a) 80 , (b) 50 and (c) $30 \mathrm{mV} \mathrm{s}^{-1}$.

Fig. 4. Variations of anodic peak current of saturated ferrocene (a) in the emulsion, (b) in the supernatant, and (c) in water phase against square-roots of the scan rate.

Fig. 5. Voltammograms of ferrocene in the centrifuged supernatant of the emulsion including $0.4 \mathrm{M} \mathrm{NaClO}_{4}$ in the aqueous phase + 0.4 M TBAP in the NB phase(a) and in ferrocene-saturated water including $0.4 \mathrm{M} \mathrm{NaClO}_{4}$ (b) at the glassy carbon electrode 3 $\mathrm{mm}$ in diameter for $v=30 \mathrm{mV} \mathrm{s}^{-1}$. 


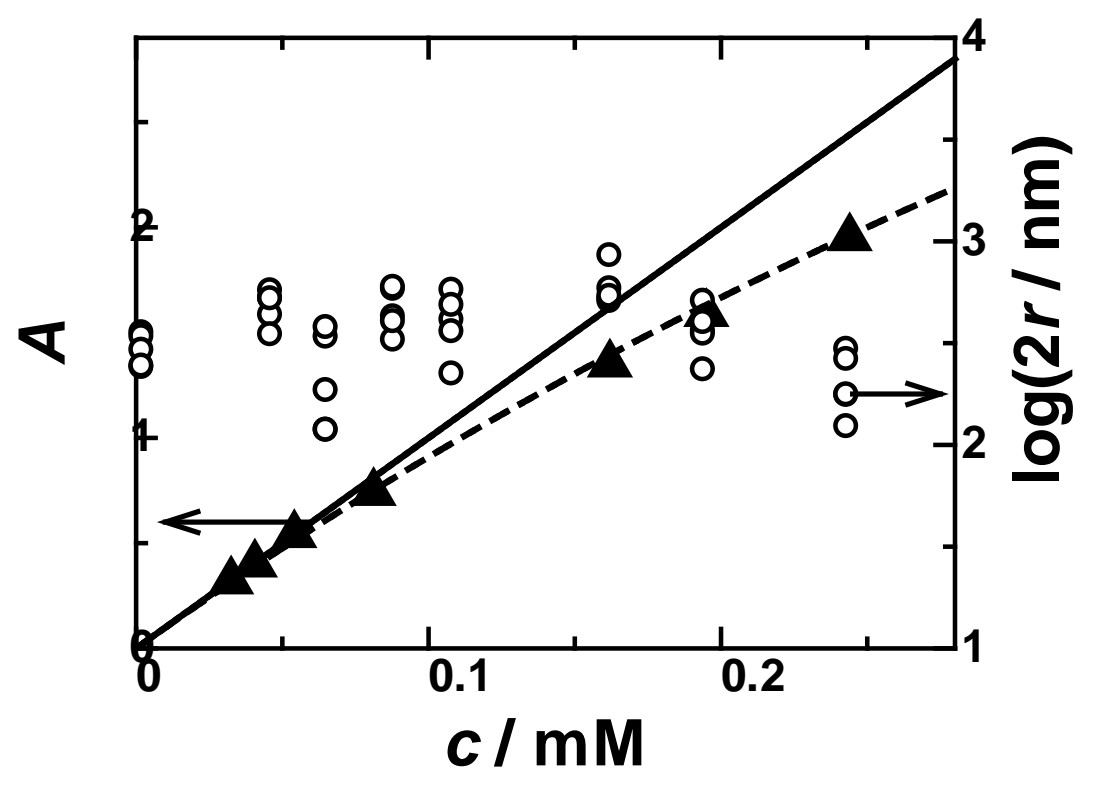

Figure 1

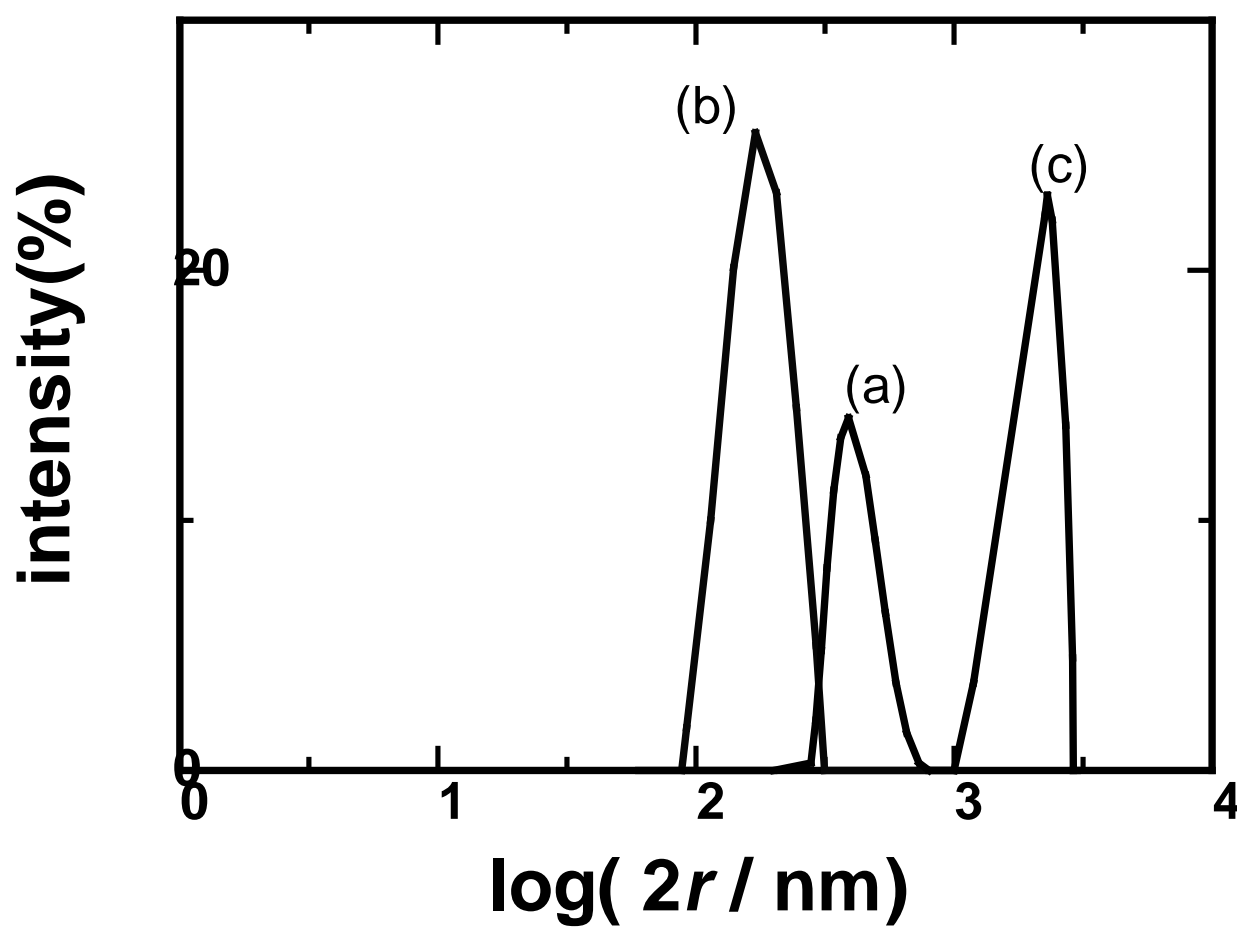

Figure 2 


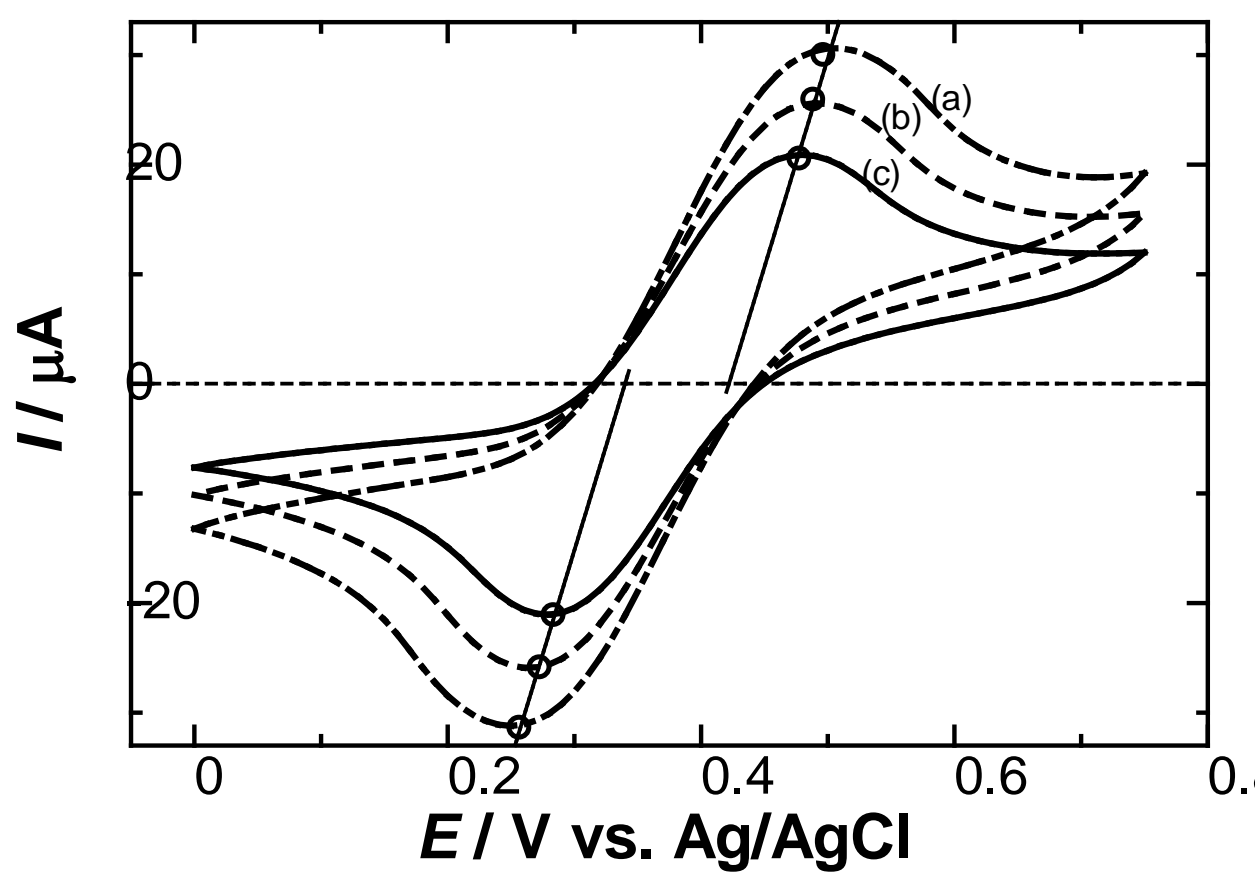

Figure 3

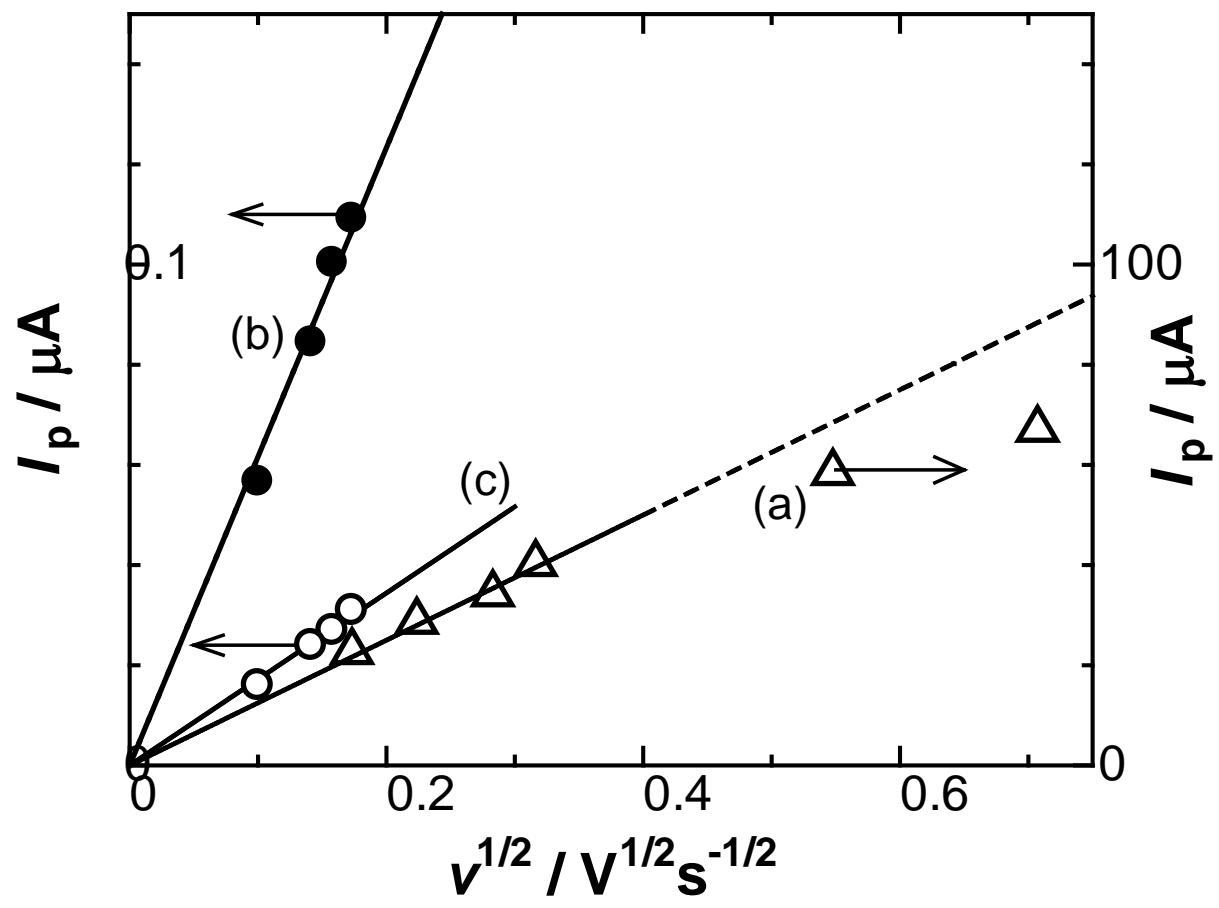

Figure 4 


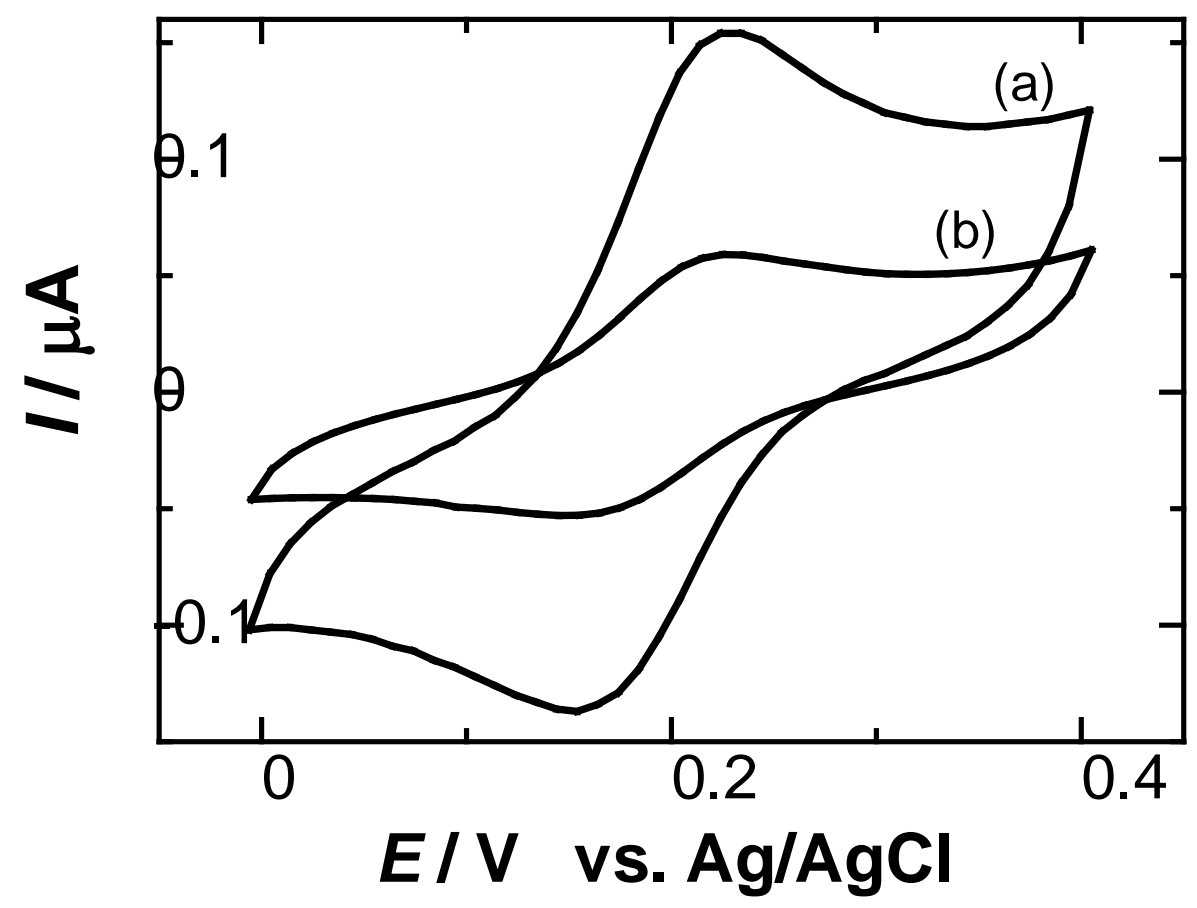

Figure 5 


\section{References}

[1] A. W. Adamson, Physical Chemistry of Surfaces, 3rd ed. John Wiley \& Sons, New York 1976, pp.491-508.

[2] E. Dickinson, Pure App. Chem. 64 (1992) 1721.

[3] I. M. Lifshitz, V. V. Slyozov, J. Phys. Chem. Solids, 19 ( 1961) 35.

[4] C. Wagner, Z. Electrochem. 65 (1961) 581.

[5] E. Fredrick, P, Walstra, K, Dewettinck, Adv. Colloid Interface Sci. 153 (2010) 30.

[6] S. Pautot, B. J. Frisken, J.-X. Cheng, X. S. Xie, D. A. Weitz, Langmuir, 19 (2003) 10281.

[7] Y. A. Shchipunov, P. Schmiedel, Langmuir, 12 (1996) 6443.

[8] H. Gonza’lez-Ochoa, L. Ibarra-Bracamontes, J. L. Arauz-Lara, Langmuir 19 (2003) 7837.

[9] S. Sacanna, W. K. Kegel, A. P. Philipse, Langmuir 23 (2007) 10486.

[10] T. Kakiuchi, Anal. Chem. 79 (2007) 6442.

[11] K. Aoki, M. Li, J. Chen, T. Nishiumi, Electrochem. Commn. 11 (2009) 239.

[12] K. Aoki, J. Colloid Interface Sci. (2010) submitted.

[13] H. H. Girault, D. J. Schiffrin. Electroanalytical Chemistry, Vol. 15 A, J. Bard (Ed.), p. 1, Marcel Dekker, New York (1989).

[14] J. Koryta, P. Vanysek. Advances in Electrochemistry and Electrochemical Engineering, Vol.12, H. Gerisher and C. W. Tobias (Eds.), p. 113, Wiley, New York (1996).

[15] P. Vanysek. Modern Techniques in Electroanalysis, p. 337, Wiley, New York (1996).

[16] Z. Samec, E. Samcová, H. H. Girault, Talanta 63 (2004) 21.

[17] Z. Samec, A. Trojanek, H. H. Girault, Electrochem. Commun. 5 (2003) 98.

[18] J. Zhang, C. J. Slevin, L. Murtomaeki, K. Kontturi, D. E. Williams, P. R. Unwin, Langmuir, 17 (2001) 821. 
[19] D. A. Higgins, R. M. Corn, J. Phys. Chem. 97 (1993) 489.

[20] B. Quinn, R. Lahtinen, L. Murtomäki, K. Kontturi, Electrochim. Acta, 44 (1998) 47.

[21] K. Nakatani, J. Yamashita, T. Negishi, T. Osakai, J. Electroanal. Chem. 575 (2005) 27.

[22] J. Zhang, P. R. Unwin, Phys. Chem. Chem. Phys.4 (2002) 3820.

[23] T. Kakiuchi, Anal. Chem. 68 (1996) 3658.

[24] H. Jensen, V. Devaud, J. Josserand, H. H. Girault, J. Electroanal. Chem. 537 (2002) 77.

[25] B. Su, N. Eugster, H. H. Girault, J. Electroanal. Chem. 577 (2005) 187.

[26] L. I. Daikhin,A. A. Kornyshev, A. M. Kuznetsov, M. Urbakh, Chem. Phys.319 (2005) 253.

[27] V. Mareček, M. Grätzl, J. Janata, J. Electroanal. Chem. 296 (1990) 537.

[28] P. W. Atkins, Physical Chemistry, Sixth edition, Oxford University Press, Oxford, 1998, p.155.

[29] I. Benjamin, Annu. Rev. Phys. Chem. 48 (1997) 407.

[30] K. Schweighofer, I. Benjamin, J. Phys. Chem. A, 103 (1999) 10274.

[31] G.M. Torrie, J.P. Valleau, J. Electroanal. Chem. 206 (1986) 69.

[32] Z. Samec, V. Marecek, D. Homolka, J. Electroanal. Chem. 187 (1985) 31.

[33] C.M. Pereira, W. Schmickler, F. Silva, M.J. Sousa, Chem. Phys. Lett. 268 (1997) 13.

[34] T. Huber, O. Pecina, W. Schmickler, J. Electroanal. Chem. 467 (1999) 203.

[35] C.M. Pereira, W. Schmickler, F. Silva, M.J. Sousa, J. Electroanal. Chem. 436 (1997) 9.

[36] B. Su, N. Eugster, H. Girault, J. Electroanal. Chem. 577 (2) (2005) 187.

[37] C.W. Monroe, M. Urbakh, A.A. Kornyshev, J. Electroanal. Chem. 582 (2005) 28. 
[38] A. G.z-Cortes, P. Armisen, M. A. Ruiz, P. Yanez-Sedeno, J. M. Pingarron, Electroanalysis 6 (1994) 1014.

[39] T. C. Franklin, R. Nnodimele, W. K. Adeniyi, D. Hunt, J. Electrochem. Soc. 135 (1988) 1944.

[40] J. Yoshida, J. Chen, K. Aoki, J. Electroanal. Chem. 553 (2003) 117.

[41] C. E. Banks, R. G. Compton, ChemPhysChem. 4 (2003) 169.

[42] J. Di, X. Gao, Talanta 51 (2000) 559.

[43] K. Aoki, J. M. Roberts, J. G. Osteryoung, Langmuir, 14 (1998) 4445.

[44] K. Aoki, T. Lei, Langmuir, 16 (2000) 10069.

[45] K. Aoki, J. Chen, Q. Ke, S. P. Armes, D. P. Randall, Langmuir, 19 (2003) 5511.

[46] H. Chen, J. Chen, K. Aoki, T. Nishiumi, Electrochim. Acta, 53 (2008) 7100.

[47] C. Xu, K. Aoki, Langmuir 20 (2004) 10194.

[48] L. Han, J. Chen, K. Aoki, J. Electroanal. Chem. 602 (2007) 123.

[49] T. Li, K. Aoki, J. Chen, T. Nishiumi, J. Electroanal. Chem, 633 (2009) 319.

[50] K. Aoki, Electrochim. Acta, 51 (2006) 6012.

[51] D. J. L. Prak, D. W. O’Sullivan, J. Chem. Eng. Data 54 (2009) 1231.

[52] E. Hogfeldt, L. Leifer, Roy. Inst. Technol., Stockholm, Arkiv foer Kemi 21 (1963) 285.

[53] Y. Guo, K. Aoki, J. Chen, T. Nishiumi, Electrochim. Acta (2010), doi:10.1016/ j.electacta.2010.11.057.

[54] J. Chen, O. Ikeda, K. Aoki, J. Electroanal. Chem. 496 (2001) 88.

[55] K. Aoki, J. Electroanal. Chem. 17 (2005) 1379. 